\title{
Physico - Chemical Analysis of Cetyl Pyridinium Chloride (CPC) Blended by Cellulose solution
}

\author{
A. Panneerselvam ${ }^{1 *}$, V.Karikalan ${ }^{2}$ \\ ${ }^{1}$ Department of Physics, Paavai Engineering College, Pachal, Tamil Nadu, India - 637018 \\ ${ }^{2}$ PG Assistant in Physics, Government Model School, Mallur, Tamil Nadu, India - 636203 \\ Corresponding Author: panneer.phy@gmail.com
}

Available online at: www.isroset.org

Received: 15/May/2019, Accepted: 19/Jun/2019, Online: 30/Jun/2019

\begin{abstract}
The ultrasonic velocity, density and viscosity in mixtures of Cetyl Pyridinium Chloride (CPC) with Cellulose derivatives (Methyl Cellulose (MC), Ethyl Cellulose (EC) and Hydroxyl Propyl Methyl Cellulose (HPMC)) in different concentration ranges are measured at different temperatures 303, 313 and $323 \mathrm{~K}$ in order to find out the Critical Micelle Concentration (CMC) of Surfactant / Cellulose interaction. From the experimental data, other related acoustical parameters such as adiabatic compressibility $(\beta)$, intermolecular free length $\left(\mathrm{L}_{\mathrm{f}}\right)$, internal pressure $\left(\pi_{\mathrm{i}}\right)$, Rao's constant $\left(\mathrm{R}_{\mathrm{a}}\right)$, absorption coefficient $\left(\alpha / \mathrm{f}^{2}\right)$, free volume $\left(\mathrm{V}_{\mathrm{f}}\right)$, cohesive energy $\left(\mathrm{C}_{\mathrm{E}}\right)$, relaxation time $(\tau)$, acoustical impedance $\left(\mathrm{Z}_{\mathrm{a}}\right)$ and solvation number $\left(S_{n}\right)$ have been evaluated. All these parameters have utilized to study of various molecular interactions takes place in the solutions of CPC - Cellulose derivatives (MC, EC and HPMC). The FTIR and UV analysis also used to characterize these samples. The results are discussed in molecular interactions that prevail by hydrogen bonding.
\end{abstract}

\section{Keywords : Ultrasonic study, Cetylpyridinium Chloride (CPC), Critical Micelle Concentration (CMC)}

\section{INTRODUCTION}

The study of intermolecular interaction in the complex formation of considerable importance in the explanation of the structural properties of the molecule [1-2]. The intermolecular actions influence the structural arrangement along with the shape of the molecule [3]. Water soluble cellulose polymers have been shown to interact with surfactant species to varying degrees depending on the properties of the cellulose polymers and surfactants [4]. Cellulose derivatives have gained acceptance for cosmetic, food, adhesives, textiles, packaging and pharmaceutics uses. Surfactant and water soluble cellulose derivatives have very broad ranges of applications. CPC is a cationic compound used in some types of mouthwashes, lozenges, toothpastes, breath sprays, throat sprays and nasal sprays. Studies on surfactant - Cellulose derivatives complexes demonstrate the interest for the surface properties of such systems [5-7]. Several micellar systems have been investigated in the absence and presence of an external entity to explore the environment of the solubilization and to infer any change occurring in micellization behavior of surfactants [8-9]. Hydroxy Propyl Methyl Cellulose (HPMC) is nonionic, water-solvable cellulose ether. It is obtained by partial substitution of hydroxyl group of cellulose with hydrophobic hydroxypropyl and methyl groups. It has variety of applications in day to day life. The combined occurrence of surfactant and cellulose derivatives is found in diverse products such as cosmetics, paints, detergents, food, polymer synthesis and formulations of drugs and pesticides [1011]. The presence of a non ionic cellulose polymer in aqueous solutions of cationic surfactants causes changes in the physical properties of the micelle aggregated formed by the surfactant. Some possible types of association involving either individual surfactant molecules or surfactant cluster were discussed [12-14]. Acoustical studies of surfactant and cellulose derivatives have become increasing and important in physical, biochemical and industrially useful applications. In the present study an attempt has been made to investigate the behaviour of Cetylpyridum Chloride (CPC) and Cellulose derivatives (Methyl Cellulose (MC), Ethyl Cellulose (EC) and Hydroxy Propyl Methyl Cellulose (HPMC)), in water at different concentration and temperature 303,313 and $323 \mathrm{~K}$. 


\section{Preparation OF SAMPLE}

Cetyl Pyridinium Chloride (CPC), Methyl Cellulose (MC), Ethyl Cellulose (EC) and Hydroxy Propyl Methyl Cellulose (HPMC) were obtained from Himedia, Tamil Nadu, India. The experimental solutions were prepared by adding a known weight of Cellulose derivatives (MC, EC and HPMC) and different concentration of Cetylpyridinium Chloride (CPC) to a fixed volume of water and then stirring under reflux until clear solutions were obtained. Doubled distilled water used to prepare the stock solution.

\section{STRUCTURE OF SAMPLE}

Cetyl Pyridinium Chloride (CPC)

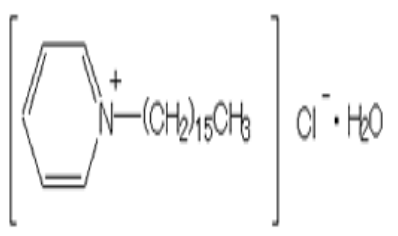

Hydroxy Propyl Methyl Cellulose (HPMC)

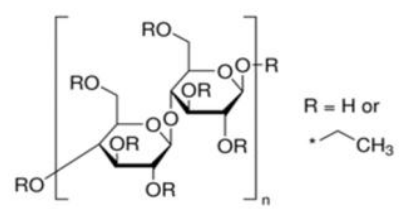

Methyl Cellulose (MC)

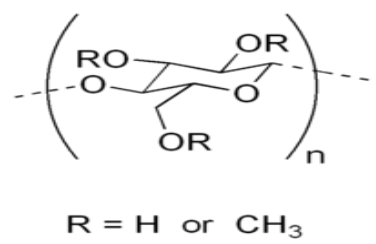

Ethyl Cellulose (EC)

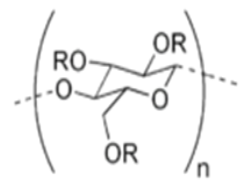

$\mathrm{R}=\mathrm{H}$ or $\mathrm{CH}_{3}$ or $\mathrm{CH}_{2} \mathrm{CH}(\mathrm{OH}) \mathrm{CH}_{3}$

\section{EXPERIMENTAL TECHNIQUES}

The ultrasonic velocity measurements in the Cetylpyridinium chloride (CPC) with Cellulose derivatives (MC, EC and HPMC) solutions were made in the ultrasonic interferometer of fixed frequency $2 \mathrm{MHz}$ (Model F 81 Mittal enterprises, New Delhi, India) and at different temperatures $(303,313$ and $323 \mathrm{~K})$. The temperature was maintained constant by circulating water from a thermostatically controlled $\left( \pm 0.1^{\circ} \mathrm{C}\right)$ digital water bath. The values of densities at different temperatures were measured using specific gravity bottle by standard procedure and the viscosity is measured using Ostwald's viscometer with an accuracy of $\pm 0.001 \%$ calibrated with double distilled water. The FTIR Spectrum for these samples using Fourier Transform Infrared Spectrometer (Spectrum RX, Perkin Elmer). The powder samples of CPC/MC, CPC/EC and CPC/HPMC at 1:1 ratio, these samples were mixed with $\mathrm{KBr}$ powder to form a pellet and placed in a sample cup and measured [15]. The entire FTIR spectrums were recorded in the range of $4000-400 \mathrm{~cm}^{-1}$. The UV - Vis Spectrometer (Model - Lamber 35 - Perkin Elmer) the surfactant / Cellulose derivatives aqueous solutions at different concentrations. All the UV sample were recorded in the range $(1000-400 \AA)$.

\section{Physical PaRameter}

Thermodynamic parameters such as adiabatic compressibility $(\beta)$, intermolecular free length $\left(\mathrm{L}_{\mathrm{f}}\right)$, internal pressure $\left(\pi_{\mathrm{i}}\right)$, acoustic impedance $\left(\mathrm{z}_{\mathrm{a}}\right)$ and solvation number $\left(\mathrm{S}_{\mathrm{n}}\right)$ have been calculated from empirical Jacobson's relations [16].

i) Adiabatic compressibility

$$
\beta=1 / u^{2} \rho
$$

has been calculated from the $u$ - ultrasonic velocity and $\rho$ - density of the medium using the Newton - Laplace equation.

ii) Intermolecular free length

$$
\mathrm{L}_{\mathrm{f}}=\mathrm{K}_{\mathrm{T}} \beta^{1 / 2}
$$

Where $\mathrm{K}_{\mathrm{T}}$ - temperature dependent constant known as Jacobson's constant $\left(\mathrm{K}_{\mathrm{T}}=2.131 \times 10^{-6}\right)$ and $\beta$ is the adiabatic compressibility

iii) Internal pressure 


$$
\pi_{\mathrm{i}}=\mathrm{bRT}[\mathrm{K} \eta / \mathrm{u}]^{1 / 2} \rho^{2 / 3} / \mathrm{M}^{7 / 6}
$$

(Where, $\mathrm{b}$ stands for cubic packing, which is assumed to be 2 for all liquids, T-absolute temperature in Kelvin, Where $M_{\text {eff }}$ - effective molecular weight of the mixture $\left(M_{e f f}=\sum m_{i} x_{i}\right.$, where $m_{i}$ and $x_{i}$ are the molecular weight and mole fraction of individual constituents, respectively $\mathrm{K}$ is a temperature independent constant which is equal to $4.281 \times 10^{9}$ for all liquids, $\mathrm{R}$ is the universal gas constant, $\eta$-Viscosity of the solution).

(iv) Rao's constant

$$
\mathrm{R}_{\mathrm{a}}=(\mathrm{M} / \rho)(\mathrm{u})^{1 / 3}
$$

(v) Relaxation time

$$
\tau=4 / 3 \beta \eta
$$

(vi) Acoustic impedance

$$
\mathrm{Za}=\rho \mathrm{u}
$$

(vii) Absorption coefficient

$$
\alpha / f^{2}=\left(8 \pi^{2} \eta / 3 \rho u^{2}\right)
$$

(viii) Free Volume

$$
\mathrm{V}_{\mathrm{f}}=\left(\mathrm{M}_{\mathrm{eff}} \mathrm{u} / \mathrm{K} \eta\right)^{3 / 2}
$$

(ix) Cohesive energy

$$
\mathrm{CE}=\mathrm{V}_{\mathrm{f}} \pi_{\mathrm{i}}
$$

(x) Solvation number

$$
\mathrm{Sn}=\mathrm{M}_{2} / \mathrm{M}_{1}[1-((\beta) / \beta \mathrm{o})][(100-\mathrm{x}) / \mathrm{x}]
$$

Where $\mathrm{M}_{1}, \mathrm{M}_{2}$ - molecular weight of the solvent and solute, $\beta$ and $\beta_{\mathrm{o}}$ - adiabatic compressibility of the solution and solvent

\section{RESULTS AND DISCUSSION}

The aqueous property of ultrasonic velocity, density and viscosity of CPC/MC, CPC/EC and CPC/HPMC at different temperature 303,313 and $323 \mathrm{~K}$ are presented in tables 1,3 and 5 . The thermo acoustical parameters such as adiabatic compressibility $(\beta)$, intermolecular free length $\left(\mathrm{L}_{\mathrm{f}}\right)$, internal pressure $\left(\pi_{\mathrm{i}}\right)$, Rao's constant $\left(\mathrm{R}_{\mathrm{a}}\right)$, absorption coefficient $\left(\alpha / \mathrm{f}^{2}\right)$, free volume $\left(V_{f}\right)$, cohesive energy $\left(C_{E}\right)$, relaxation time $(\tau)$, acoustical impedance $\left(Z_{a}\right)$ and solvation number $\left(S_{n}\right)$ were calculated using acoustical relations. From the variation of ultrasonic velocity values with the ratio of surfactant $\mathrm{CPC} / \mathrm{EC}$ a velocity maxima is observed at the critical ratio 4:1. At the ratio of 4:1 the velocity attains its maximum value and then gradually drops down. However, in general CPC / MC and CPC / HPMC, velocity maximum is observed at the critical ratio $3: 1$ and then gradually decreases [17]. The above variation is shows in figures 1,4 and 7 . From the conformation of the surfactant and cellulose derivates tend to form hydrogen bonding between them. This hydrogen bonding formation may reaches a saturation value at a critical concentration ratio of 4:1 for CPC / EC, 3:1 for CPC / MC and CPC / HPMC. But the density variations, the maximum densities are recorded for CPC / EC whereas CPC / MC and CPC / HPMC density remains minimum.

From the figures 2, 5 and 8 the adiabatic compressibility is found to decreases with increases in the ratio of CPC / EC upto 4:1 and the ratio of CPC / MC and CP / HPMC upto 3:1 beyond this ratio when the CPC concentration is increased the velocity tends to decreases and adiabatic compressibility is found to increases. This indicates the breaking of surfactant cellulose derivatives complexes beyond the saturation point of 4:1 (CPC / EC) and 3:1 (CPC / MC and CPC / HPMC) which may cause the intermolecular free length $\left(\mathrm{L}_{\mathrm{f}}\right)$ to increase beyond the critical micelle concentration. The decrease in intermolecular free length with increase in solute concentration indicates that there is a significant interaction between the solute and solvent molecules, suggesting a structure promoting behaviour on the addition of solute [18-19]. Due to thermal expansion of liquids as increase in temperature causes free length to increase [20]. Intermolecular free length is comparatively low and internal pressure is quit high [20] in the case of CPC / EC system. This may be due to the cohesion between solvent and solute molecules and reduction in the hydrodynamic volume. Such an observation is made in the case of Cellulose acetate in cydohexane [21]. The value of internal pressure decreases with increase in concentration of solutes, where as decrease with elevation of temperature. The reduction thermal pressure may be due to the loosening of cohesive forces leading to breaking up the structure of solvent [22].

In this study, the Rao's constant increases with increase in concentration of surfactant solution in cellulose derivatives suggest that solute - solvent interaction is varied and it is maximum at higher concentration of surfactant. The non - linear 
variation of Rao's constant and the gradual increases of acoustic impedance in all the three systems clearly indicate the solute solvent interaction exists in the system but it is dominant in CPC + EC system than in the other two systems. From the figures 3,6 and 9 the absorption coefficient $\left(\alpha / \mathrm{f}^{2}\right)$ increases with increase in concentration and decreases with increases in temperature indicate the association through hydrogen bonding and strong interaction between the solute and solvent. However, if the concentration of CPC is increased, it can be seen that, the absorption coefficient also increases. This may due to the fact that the maximum reaction takes place at higher concentration. The cohesive energy also same fashion as that of absorption coefficient. Similar observations were reported for the solution of ethyl cellulose in alcohols [23]. If the internal Pressure decreases correspondingly free volume increases with increase in concentration of CPC. The relaxation time $(\tau)$ behaves in the same manner as that of free volume and the relaxation times is found to be high for CPC/EC system which confirms strong association between Surfactant / Cellulose - solvent in that system when compared to other two systems studied.

Table 1. Ultrasonic velocity and related acoustical parameters in aqueous $\mathrm{CPC}+\mathrm{MC}$ at different temperatures

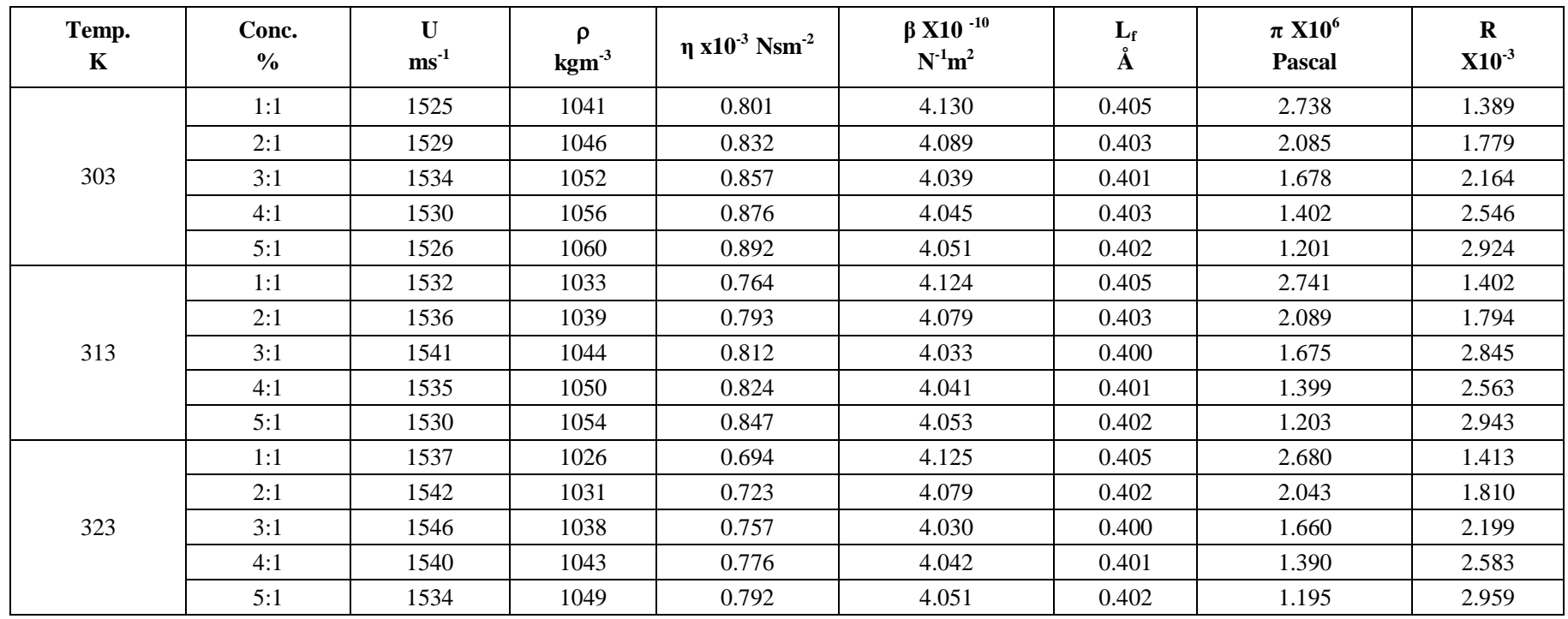

Table 2. Ultrasonic absorption coefficient and related acoustical parameters in aqueous $\mathrm{CPC}+\mathrm{MC}$ at different temperature

\begin{tabular}{|c|c|c|c|c|c|c|c|}
\hline $\begin{array}{c}\text { Temp. } \\
\text { K }\end{array}$ & $\begin{array}{c}\text { Conc. } \\
\%\end{array}$ & $\begin{array}{l}\alpha / f^{2} \times 10^{-15} \\
N p m^{-1} s^{2}\end{array}$ & $\begin{array}{l}V_{f} \times 10^{-15} \\
\mathrm{~m}^{3} \mathrm{~mol}^{-1}\end{array}$ & $\begin{array}{c}\mathbf{C E} \\
\mathbf{x} 10^{-8}\end{array}$ & $\tau \times \mathrm{x10}^{-12} \mathrm{Sec}$ & $\begin{array}{c}\mathrm{z}_{\mathrm{a}} \times 10^{6} \\
\mathrm{kgm}^{-2} \mathrm{~s}^{2}\end{array}$ & $S_{n}$ \\
\hline \multirow{4}{*}{303} & $1: 1$ & 5.705 & 0.215 & 5.905 & 4.41 & 1.587 & -17 \\
\hline & $3: 1$ & 5.933 & 0.474 & 7.957 & 4.61 & 1.613 & 37 \\
\hline & $4: 1$ & 6.089 & 0.626 & 8.789 & 4.72 & 1.615 & 29 \\
\hline & $5: 1$ & 6.226 & 0.795 & 9.557 & 4.81 & 1.617 & 23 \\
\hline \multirow{4}{*}{313} & $2: 1$ & 5.537 & 0.301 & 6.536 & 4.31 & 1.595 & 11 \\
\hline & $3: 1$ & 5.588 & 0.440 & 7.375 & 4.36 & 1.608 & 31 \\
\hline & $4: 1$ & 5.704 & 0.574 & 8.029 & 4.43 & 1.611 & 25 \\
\hline & $5: 1$ & 5.899 & 0.738 & 8.915 & 4.57 & 1.612 & 21 \\
\hline \multirow{2}{*}{323} & $1: 1$ & 4.897 & 0.175 & 4.714 & 3.81 & 1.576 & -27 \\
\hline & $2: 1$ & 5.028 & 0.273 & 5.600 & 3.93 & 1.589 & 8 \\
\hline
\end{tabular}


Table 3. Ultrasonic velocities and related acoustical Parameters in aqueous CPC $+\mathrm{EC}$ at different temperature

\begin{tabular}{|c|c|c|c|c|c|c|c|c|}
\hline $\begin{array}{c}\text { Temp. } \\
\text { K }\end{array}$ & $\begin{array}{c}\text { Conc. } \\
\%\end{array}$ & $\begin{array}{c}\mathrm{U} \\
\mathrm{ms}^{-1}\end{array}$ & $\begin{array}{c}\rho \\
\mathbf{k g m}^{-3}\end{array}$ & $\eta \mathbf{x}_{2} \mathbf{N s m}^{-3}$ & $\begin{array}{c}\beta \times 10 \\
\mathbf{N}^{-1} \mathbf{m}^{2}\end{array}$ & $\begin{array}{l}\mathbf{L}_{\mathbf{f}} \\
\AA\end{array}$ & $\begin{array}{l}\pi \mathrm{X}^{6} 0^{6} \\
\text { Pascal }\end{array}$ & $\begin{array}{c}\mathbf{R} \\
\mathbf{X 1 0 ^ { - 3 }}\end{array}$ \\
\hline \multirow{4}{*}{303} & $1: 1$ & 1528 & 1061 & 1.260 & 4.036 & 0.4008 & 3.474 & 1.364 \\
\hline & $2: 1$ & 1534 & 1074 & 1.612 & 3.956 & 0.3969 & 2.949 & 1.734 \\
\hline & $3: 1$ & 1540 & 1083 & 1.836 & 3.893 & 0.3937 & 2.500 & 2.105 \\
\hline & $4: 1$ & 1547 & 1092 & 2.247 & 3.826 & 0.3903 & 2.283 & 2.471 \\
\hline \multirow{4}{*}{313} & $1: 1$ & 1535 & 1048 & 0.999 & 4.049 & 0.4015 & 3.162 & 1.383 \\
\hline & $2: 1$ & 1541 & 1059 & 1.150 & 3.976 & 0.3978 & 2.543 & 1.762 \\
\hline & $3: 1$ & 1546 & 1072 & 1.456 & 3.902 & 0.3941 & 2.279 & 2.129 \\
\hline & $4: 1$ & 1551 & 1081 & 1.867 & 3.845 & 0.3912 & 2.133 & 2.498 \\
\hline \multirow{2}{*}{323} & $4: 1$ & 1560 & 1071 & 1.328 & 3.836 & 0.3908 & 1.839 & 2.252 \\
\hline & $5: 1$ & 1557 & 1076 & 1.739 & 3.843 & 0.3911 & 1.790 & 2.898 \\
\hline
\end{tabular}

Table 4. Ultrasonic absorption coefficient and related acoustical parameters in aqueous $\mathrm{CPC}+\mathrm{EC}$ at different temperature

\begin{tabular}{|c|c|c|c|c|c|c|c|}
\hline $\begin{array}{c}\text { Temp. } \\
\text { K }\end{array}$ & $\begin{array}{c}\text { Conc. } \\
\%\end{array}$ & $\begin{array}{l}\alpha / f^{2} \times 10^{-15} \\
N p m^{-1} s^{2}\end{array}$ & $\begin{array}{l}V_{f} \times 10^{-15} \\
\mathbf{m}^{3} \mathbf{m o l}^{-1}\end{array}$ & $\begin{array}{c}\text { CE } \\
\mathbf{x 1 0 ^ { - 8 }}\end{array}$ & $\tau \times 10^{-12} \mathrm{Sec}$ & $\begin{array}{c}\mathrm{z}_{\mathrm{a}} \times 10^{6} \\
\mathrm{kgm}^{-2} \mathrm{~s}^{2}\end{array}$ & $\mathbf{S}_{\mathbf{n}}$ \\
\hline \multirow{3}{*}{303} & $2: 1$ & 10.932 & 0.905 & 26.696 & 8.50 & 1.647 & 83 \\
\hline & $3: 1$ & 12.204 & 1.495 & 37.379 & 9.52 & 1.667 & 95 \\
\hline & $5: 1$ & 16.275 & 3.760 & 76.791 & 12.72 & 1.690 & 98 \\
\hline \multirow{4}{*}{313} & $1: 1$ & 6.929 & 0.303 & 9.589 & 5.39 & 1.608 & 57 \\
\hline & $2: 1$ & 7.802 & 0.549 & 13.968 & 6.09 & 1.631 & 76 \\
\hline & $3: 1$ & 9.664 & 1.061 & 24.212 & 7.57 & 1.657 & 95 \\
\hline & $4: 1$ & 12.170 & 1.990 & 42.462 & 9.57 & 1.676 & 106 \\
\hline \multirow{4}{*}{323} & $2: 1$ & 6.557 & 0.424 & 10.065 & 5.14 & 1.613 & 48 \\
\hline & $3: 1$ & 7.436 & 0.724 & 14.810 & 5.85 & 1.641 & 80 \\
\hline & $4: 1$ & 8.587 & 1.204 & 22.161 & 6.79 & 1.670 & 101 \\
\hline & $5: 1$ & 11.301 & 2.226 & 39.850 & 8.90 & 1.673 & 91 \\
\hline
\end{tabular}


Table 5. Ultrasonic velocity and related acoustical Parameters in aqueous CPC + HPMC at different temperature

\begin{tabular}{|c|c|c|c|c|c|c|c|c|}
\hline $\begin{array}{c}\text { Temp. } \\
\text { K }\end{array}$ & $\begin{array}{c}\text { Conc. } \\
\%\end{array}$ & $\begin{array}{c}\mathbf{U} \\
\mathbf{m s}^{-1}\end{array}$ & $\begin{array}{c}\rho \\
\mathbf{k g m}^{-3}\end{array}$ & $\eta \underset{2}{\eta \times 10^{-3}} \mathrm{Nsm}^{-}$ & $\begin{array}{c}\beta \mathrm{X}^{10}{ }^{-10} \\
\mathbf{N}^{-1} \mathbf{m}^{2}\end{array}$ & $\begin{array}{l}\mathbf{L}_{\mathrm{f}} \\
\AA\end{array}$ & $\begin{array}{l}\pi \mathrm{X10}{ }^{6} \\
\text { Pascal }\end{array}$ & $\begin{array}{c}\mathbf{R} \\
\mathbf{X 1 0 ^ { - 3 }}\end{array}$ \\
\hline \multirow{3}{*}{303} & $1: 1$ & 1526 & 1050 & 0.983 & 4.089 & 0.403 & 3.049 & 1.377 \\
\hline & $3: 1$ & 1536 & 1071 & 1.349 & 3.957 & 0.396 & 2.129 & 2.126 \\
\hline & $4: 1$ & 1532 & 1075 & 1.736 & 3.963 & 0.397 & 1.996 & 2.501 \\
\hline \multirow{5}{*}{313} & $1: 1$ & 1533 & 1037 & 0.836 & 4.103 & 0.404 & 2.874 & 1.397 \\
\hline & $2: 1$ & 1538 & 1049 & 0.981 & 4.030 & 0.400 & 2.336 & 1.777 \\
\hline & $3: 1$ & 1543 & 1058 & 1.126 & 3.969 & 0.397 & 1.989 & 2.156 \\
\hline & $4: 1$ & 1540 & 1062 & 1.479 & 3.970 & 0.398 & 1.883 & 2.536 \\
\hline & $5: 1$ & 1536 & 1064 & 1.892 & 3.983 & 0.399 & 1.807 & 2.918 \\
\hline \multirow{2}{*}{323} & $4: 1$ & 1544 & 1050 & 1.173 & 3.994 & 0.399 & 1.715 & 2.563 \\
\hline & $5: 1$ & 1539 & 1055 & 1.489 & 4.001 & 0.400 & 1.643 & 2.945 \\
\hline
\end{tabular}

Table 6. Ultrasonic absorption coefficient and related acoustical Parameters in aqueous CPC + HPMC at different temperature

\begin{tabular}{|c|c|c|c|c|c|c|c|}
\hline $\begin{array}{c}\text { Temp. } \\
\text { K }\end{array}$ & $\begin{array}{c}\text { Conc. } \\
\%\end{array}$ & $\begin{array}{c}\alpha / f^{2} \times 10^{-15} \\
N p m^{-1} s^{2}\end{array}$ & $\begin{array}{l}V_{f} \times 10^{-15} \\
\mathrm{~m}^{3} \mathrm{~mol}^{-1}\end{array}$ & $\begin{array}{c}\mathrm{CE} \\
\mathbf{x 1 0 ^ { - 8 }}\end{array}$ & $\tau \times \mathrm{x}^{-12} \mathrm{Sec}$ & $\begin{array}{c}z_{\mathrm{a}} \times 10^{6} \\
\mathrm{kgm}^{-2} \mathrm{~s}^{2}\end{array}$ & $S_{n}$ \\
\hline \multirow{4}{*}{303} & $1: 1$ & 6.926 & 0.293 & 8.949 & 5.359 & 1.602 & 17 \\
\hline & $2: 1$ & 7.859 & 0.533 & 13.147 & 6.096 & 1.624 & 47 \\
\hline & $3: 1$ & 9.138 & 0.937 & 19.977 & 7.116 & 1.645 & 67 \\
\hline & $4: 1$ & 11.808 & 1.751 & 34.973 & 9.171 & 1.646 & 57 \\
\hline \multirow{5}{*}{313} & $1: 1$ & 5.883 & 0.231 & 6.659 & 4.572 & 1.589 & 12 \\
\hline & $2: 1$ & 6.758 & 0.431 & 10.080 & 5.27 & 1.613 & 47 \\
\hline & $3: 1$ & 7.616 & 0.720 & 14.326 & 5.958 & 1.632 & 65 \\
\hline & $4: 1$ & 10.025 & 1.388 & 26.146 & 7.887 & 1.635 & 55 \\
\hline & $5: 1$ & 12.901 & 2.479 & 44.816 & 10.046 & 1.634 & 48 \\
\hline \multirow{2}{*}{323} & $4: 1$ & 7.979 & 0.984 & 16.887 & 6.246 & 1.621 & 38 \\
\hline & $5: 1$ & 10.180 & 1.736 & 28.538 & 7.943 & 1.623 & 33 \\
\hline
\end{tabular}




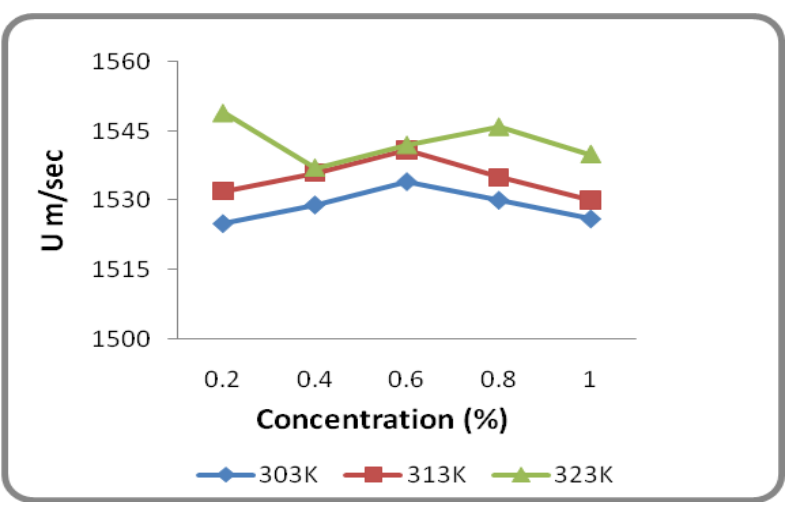

Figure 1. Ultrasonic Velocity Vs Concentration of $C P C+M C$ in aqueous solution at different temperature

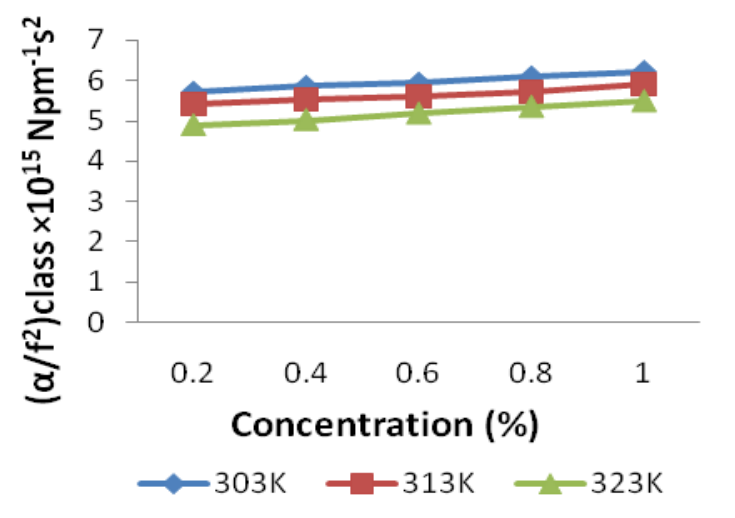

Figure 3. Absorption coefficient Vs Concentration of $C P C+M C$ in aqueous solution at different temperature

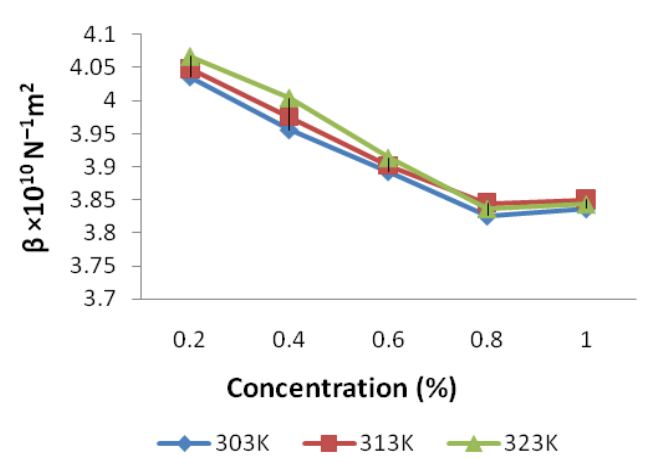

Figure 5. Adiabatic compressibility Vs Concentration of $C P C+E C$ in aqueous solution at different temperature

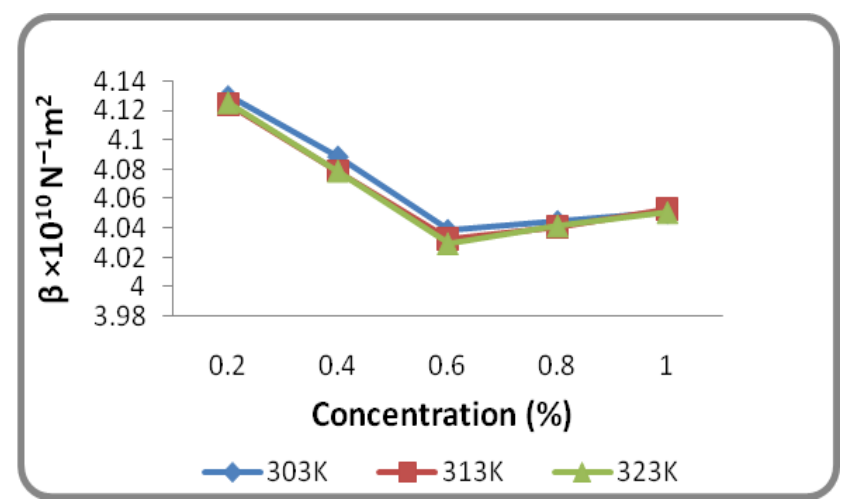

Figure 2. Adiabatic compressibility Vs Concentration of $C P C+M C$ in aqueous solution at different temperature

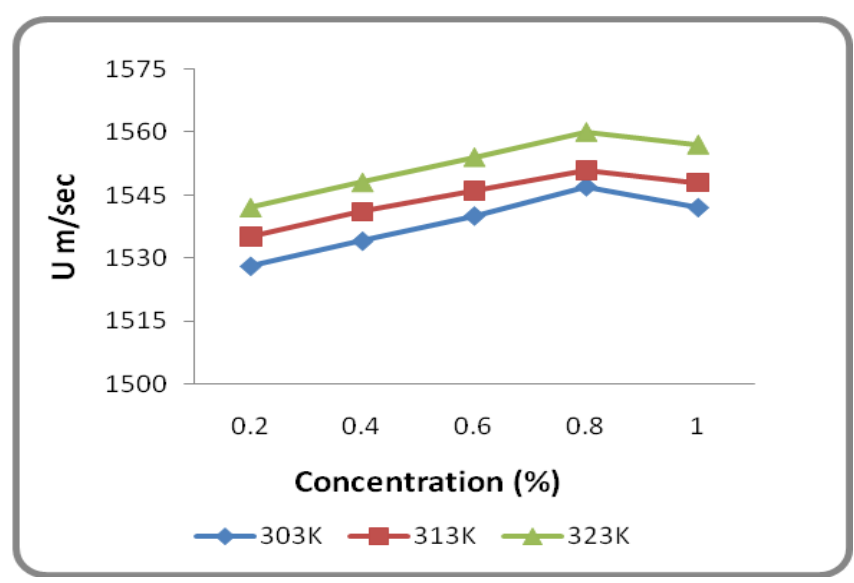

Figure 4. Ultrasonic Velocity Vs Concentration of $C P C+E C$ in aqueous solution at different temperature

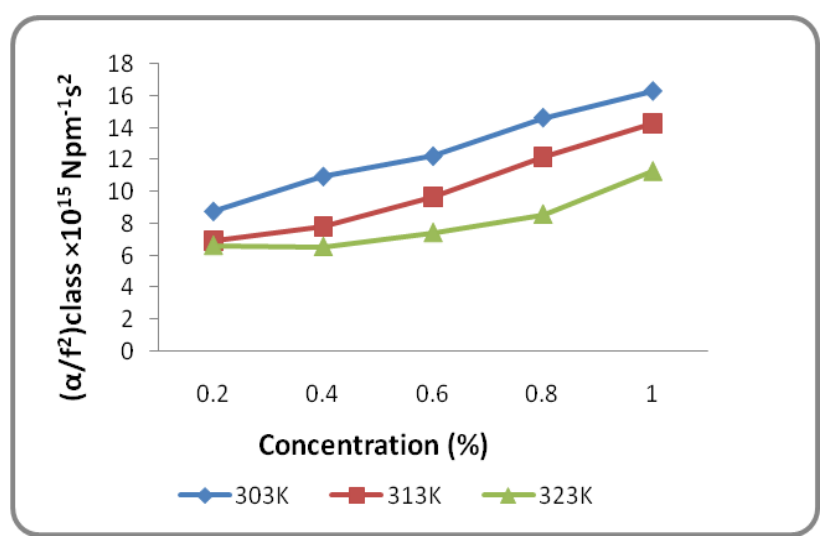

Figure 6. Absorption coefficient Vs Concentration of $C P C+E C$ in aqueous solution at different temperature 


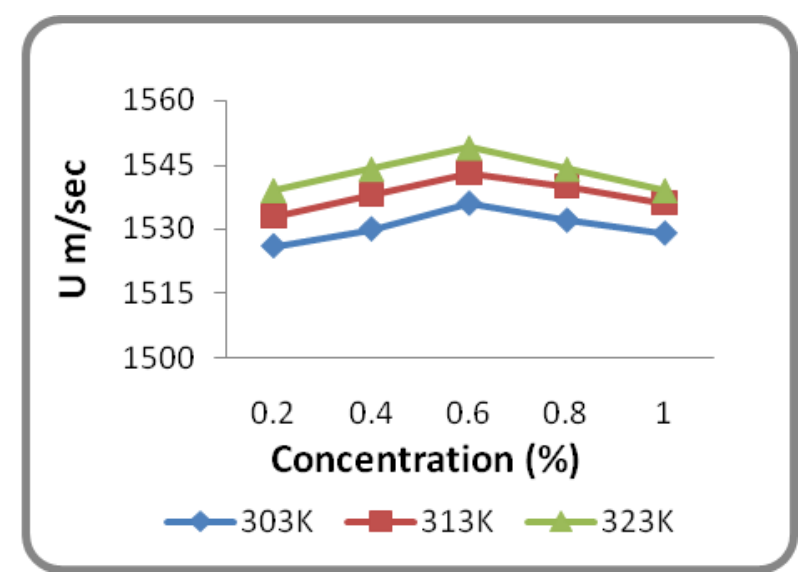

Figure 7. Ultrasonic Velocity Vs Concentration of $C P C+H P M C$ in aqueous solution at different temperature

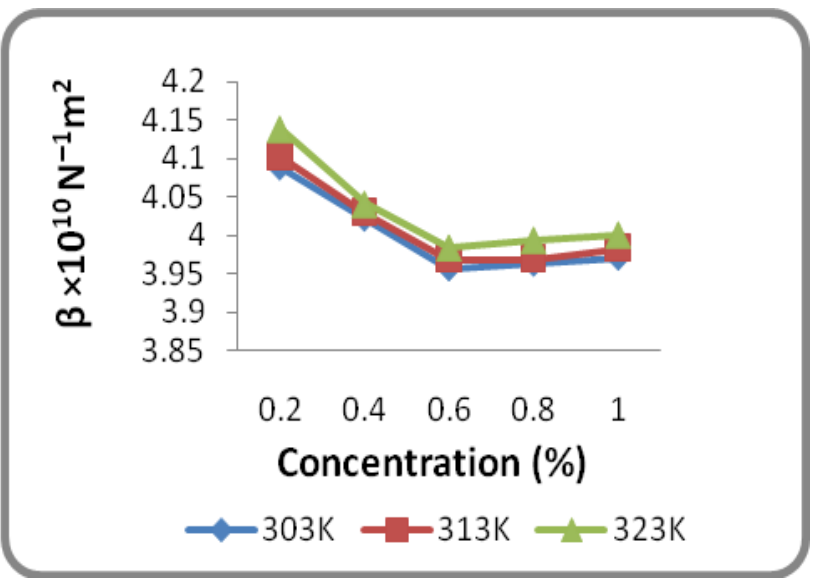

Figure 8. Adiabatic compressibility Vs Concentration of CPC $+H P M C$ in aqueous solution at different temperature

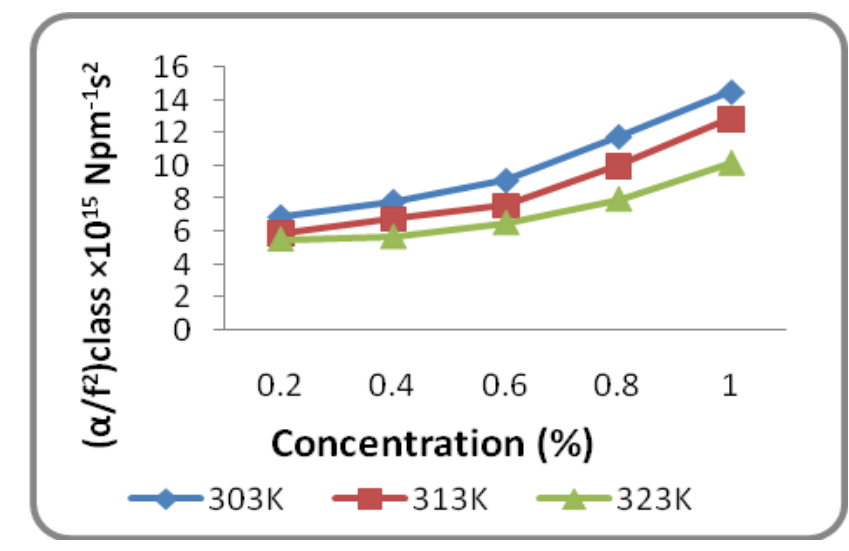

Figure 9. Absorption coefficient Vs Concentration of CPC + HPMC in aqueous solution at different temperature

Solvation is the attraction of molecules in the solvent [15]. The Solvation number (Sn) increases with increase in concentration upto the CMC level 4:1 of CPC / EC and 3:1 of CPC / MC and CPC / HPMC and then decreased. However, the solvation number decreased with the increases in temperature [24]. This suggests significantly strong interaction in both the systems. The increase in (Sn) supports Structure Maker (SN) tendency of surfactants. But decreases in the value of $(\mathrm{Sn})$ at higher temperature favor presence of solute - solvent interaction. Interaction of EC with aqueous CPC is stronger as compared to interaction of MC, HPMC with CPC.

The interaction level changes in the following order

$$
\mathrm{CPC}+\mathrm{EC}>\mathrm{CPC}+\mathrm{HPMC}>\mathrm{CPC}+\mathrm{MC}
$$

Hence it may be concluded from the above discussion, the critical concentration of 4:1 of CPC / EC there is possibility from formation of molecular association complexed between Surfactant / Cellulose than compare to CPC / MC and CPC / HPMC. 


\section{FTIR ANALYSIS}

The Fourier transform infrared analysis is conducted to verify the possibility of interaction of chemical bonds between Cationic Surfactant and cellulose. FTIR is an attractive technique to evaluate structural variations on samples due to the chemical treatments. The FT-IR spectra of pure Cationic Surfactant (CPC) and CPC mixed with Methyl Cellulose, Ethyl Cellulose and Hydroxypropyl Methylcellulose samples were recorded in the transmittance mode in the range of $4000-400 \mathrm{~cm}^{-1}$ at a resolution of $1.0 \mathrm{~cm}^{-1}$. The representative spectrum for CPC is shown in figure 10 to 12 along with the corresponding spectra of pure Methyl Cellulose, Ethyl Cellulose and Hydroxypropyl Methylcellulose blended in the ratio of 1:1 respectively.

The spectrum of CPC shows the characteristic absorption of band positions and intensities observed in FTIR spectra with wave number and intensities. Figure 10 to 12 shows the IR spectra of pure CPC and CPC mixed with different cellulose derivatives (MC, EC and HPMC). From the figure, pure CPC showed characteristic IR absorption bands at $1020 \mathrm{~cm}^{-1}$ indicating the presence of C-N group, $1118 \mathrm{~cm}^{-1}$ indicates the presence of C-O-C group in aromatic ring, $1345 \mathrm{~cm}^{-1}$ indicates the presence of C-F group, $1625 \mathrm{~cm}^{-1}$ indicates the presence $\mathrm{C}=\mathrm{N}$ group, $1700 \mathrm{~cm}^{-1}$ indicates the presence of stretching of $\mathrm{C}=\mathrm{O}$ group, 3506 $\mathrm{cm}^{-1}$ indicates the presence of bending of N-H group, $3168 \mathrm{~cm}^{-1}$ and $-\mathrm{OH}$ group, which are associated with the CPC before the chemical treatments. After CPC loaded with EC, MC and HPMC sample, these bands are not observed in the FTIR spectrum. The effect of this chemical purification can be observed through main spectral bands which must be emphasized at $1572 \mathrm{~cm}^{-1}$. The band at $1572 \mathrm{~cm}^{-1}$ is absent and the band at $1250 \mathrm{~cm}^{-1}$ is reduced drastically in the FTIR spectrum of CPC loaded with EC, MC and HPMC as shown in figures $10-12$. The spectral band observed in the region $1630-1674 \mathrm{~cm}^{-1}$ for CPC and CPC loaded EC, MC and HPMC are due to the $\mathrm{O}-\mathrm{H}$ bending due to adsorbed.

The results of FTIR studies show solute - solute - solvent interaction via hydrogen bond formation through the O-H groups [25]. The strength of Hydrogen bond formation depends on the close approach of the interesting molecules. The O-H frequency of CPC is affected in the blend compositions, showed the presence of intermolecular interaction. However, CPC loaded with Ethyl Cellulose reveals (figure: 11) significant chemical interaction which is realized by observing all spectral bands of CPC even after Ethyl Cellulose loaded. Besides, FTIR studies showed that the Ethyl Cellulose distribution in the CPC was homogeneous. From the FTIR spectra, the result suggests that CPC + Ethyl Cellulose blend has stronger intermolecular interaction than CPC + Methyl Cellulose and CPC + Hydroxy Propyl Methyl Cellulose blends.

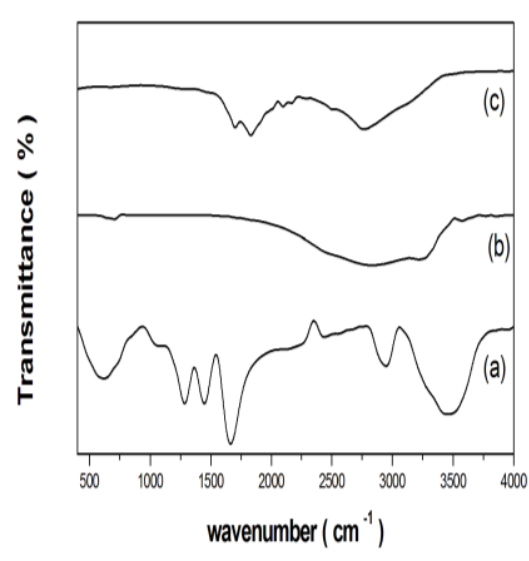

Figure 10. Overlapped FTIR Spectra for a) $C P C, b) M C$ and c) $C P C+M C$

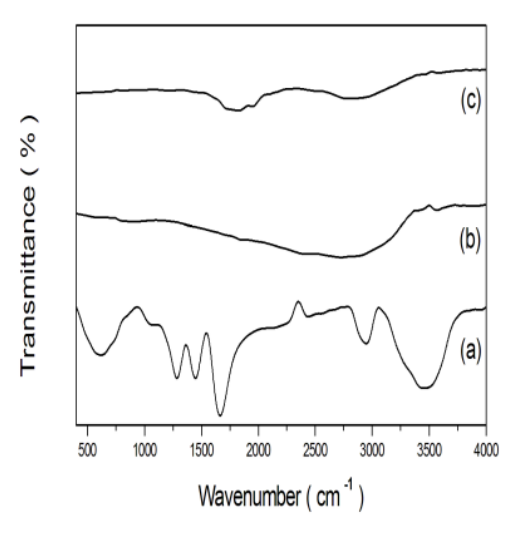

Figure 11. Overlapped FTIR Spectra for a) $C P C, b) E C$ and c) $C P C+E C$

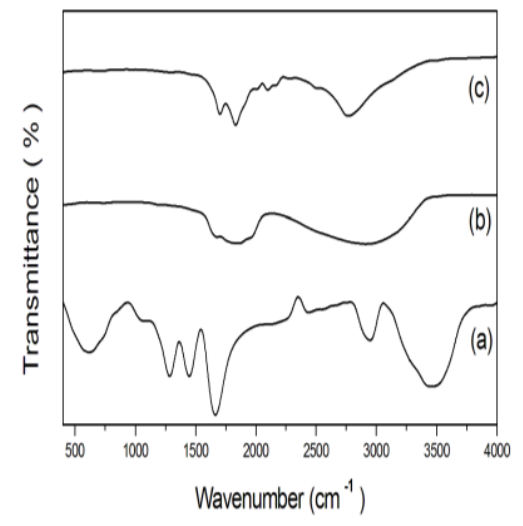

Figure 12. Overlapped FTIR Spectra for a) $C P C, b) H P M C$ and c) $C P C+H P M C$ 


\section{UV ANALYSIS}

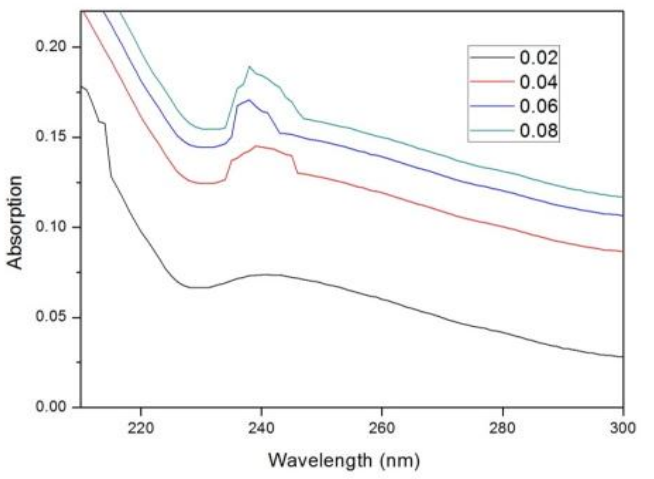

Figure 13. UV-VIS spectra for $C P C+M C$

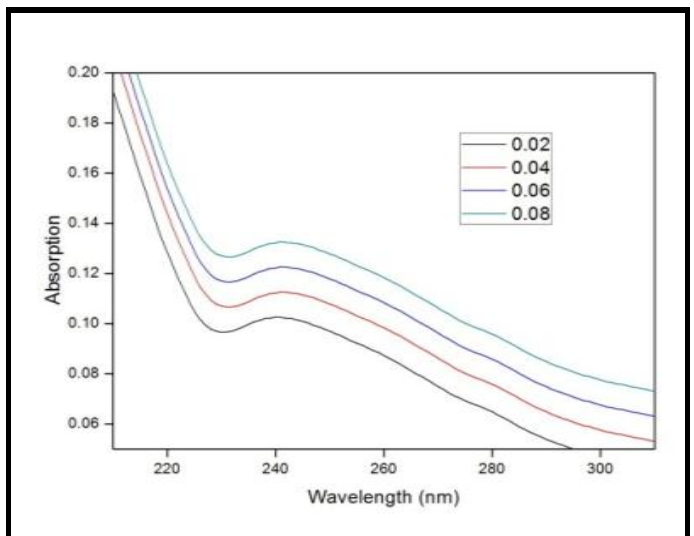

Figure 14. UV-VIS spectra for $C P C+E C$

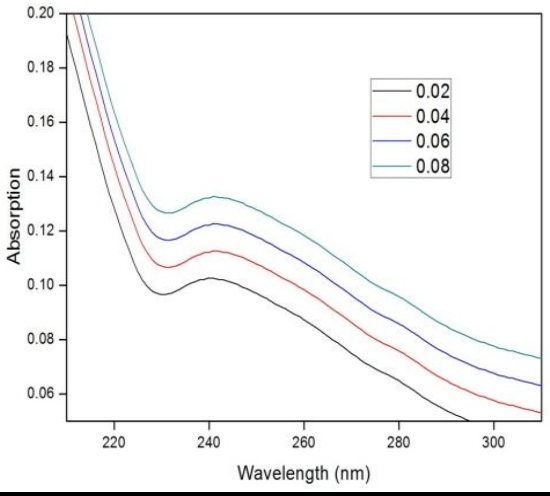

Figure 15. UV-VIS spectra for $C P C+H P M C$

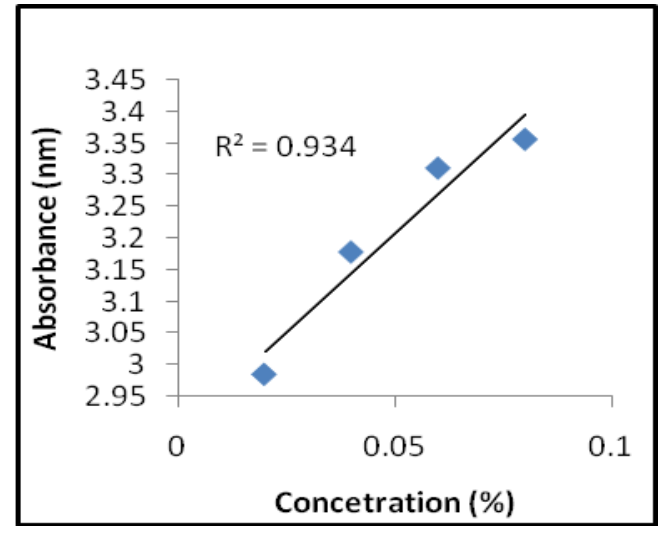

Figure 16. Lamberts-Beer linear plots for aqueous solutions of $C P C+M C$

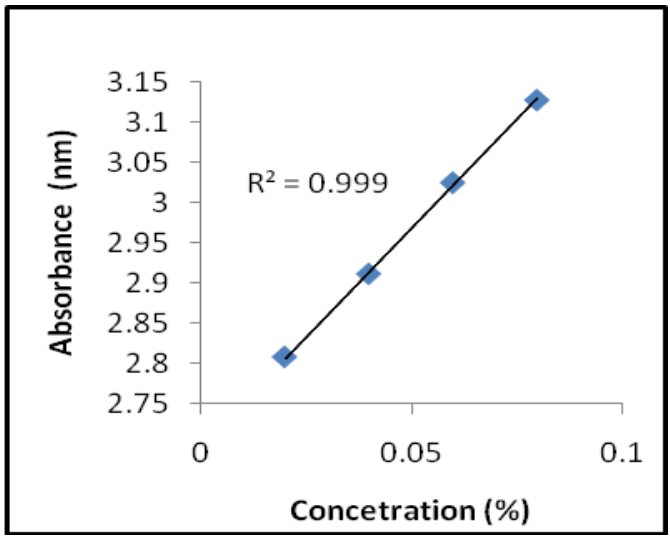

Figure 17. Lamberts - Beer linear plots for aqueous solutions of $C P C+E C$

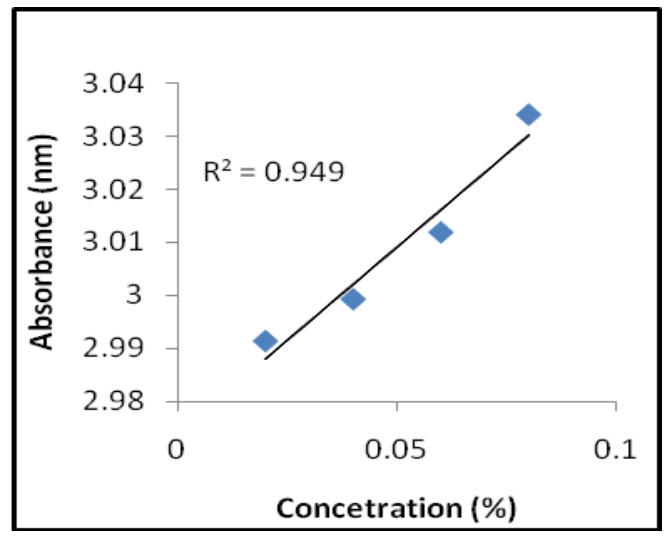

Figure 18. Lamberts - Beer linear plot for aqueous solution of $C P C+H P M C$ 
Figure 13 to 15 shows the UV - Vis spectrum of the aqueous solution of Cationic Surfactant (CPC) with Methyl Cellulose, Ethyl Cellulose and Hydroxy Propyl Methyl Cellulose at room temperature. The spectrum shows a peak with absorbance value increasing with increase in concentration. A typical Lambert - Beer behavior has been followed. The CPC + Methyl Cellulose spectra shows only one characteristic peaks at $236.4 \mathrm{~nm}$. The CPC + Ethyl Cellulose and CPC + Hydroxypropyl Methylcellulose shows only one characteristic peaks at $248.04 \mathrm{~nm}$ and $238.38 \mathrm{~nm}$. To study the effect of polarity on the UV absorption data (Table: 7). The plot concentration versus absorption is drawn and linear regression analysis has also been carried out.

Table 7. UV-VIS absorption values of CPC+MC, $\mathrm{CPC}+\mathrm{EC}$ and $\mathrm{CPC}+\mathrm{HPMC}$

\begin{tabular}{|c|c|c|}
\hline Compounds & $\begin{array}{l}\text { Concentration } \\
\left(\times 10^{-3}\right) \mathrm{mol} \mathrm{dm}^{-3}\end{array}$ & Absorption (nm) \\
\hline \multirow{5}{*}{$\mathrm{CPC}+\mathrm{MC}$} & 0.02 & 2.9864 \\
\hline & 0.04 & 3.0179 \\
\hline & 0.06 & 3.0311 \\
\hline & 0.08 & 3.0356 \\
\hline & 0.10 & 3.0707 \\
\hline \multirow{5}{*}{$\mathrm{CPC}+\mathrm{EC}$} & 0.02 & 2.8076 \\
\hline & 0.04 & 2.9112 \\
\hline & 0.06 & 3.0251 \\
\hline & 0.08 & 3.1281 \\
\hline & 0.10 & 3.1784 \\
\hline \multirow{5}{*}{$\mathrm{CPC}+\mathrm{HPMC}$} & 0.02 & 2.9914 \\
\hline & 0.04 & 2.9993 \\
\hline & 0.06 & 3.0119 \\
\hline & 0.08 & 3.0341 \\
\hline & 0.10 & 3.0476 \\
\hline
\end{tabular}

For the UV absorption analysis, a mixture of CPC + Ethyl Cellulose is extremely good correlation $\mathrm{R}^{2}=0.985 \quad$ (figure: 17) is obtained, but CPC + Methyl Cellulose and CPC + HPMC is poor correlation $R^{2}=0.873$ (figure: 16) and $R^{2}=0.974$ (figure: 18). All the correlation depends upon the solute - solvent interaction [25, 26].

\section{CONCLUSION}

From the structure of CPC with Cellulose derivatives the interaction is predominant and stronger in CPC + Ethyl cellulose when compared to CPC + Methyl cellulose and CPC + Hydroxy Propyl Methyl Cellulose. It is well know that internal pressure increases in hydrogen bonded systems. The increase in the value of acoustical impedance is an indication of strong interaction between CPC + Ethyl cellulose. Comparing the effect of addition of CPC + Ethyl cellulose shows maximum molecular interaction than CPC + Methyl cellulose and CPC + HPMC. From the FTIR spectra, CPC mixed with Ethyl cellulose reveals significant chemical interaction which is realized by observing all spectral bands of CPC even Ethyl cellulose loaded. Finally in the FTIR spectra, the result suggests that CPC + Ethyl cellulose blend has stronger intermolecular interaction than CPC + Methyl cellulose and CPC + HPMC. For the UV analysis, CPC + Ethyl cellulose is extremely good correlation compare to other two mixtures. Finally we conclude that CPC + Ethyl cellulose has been used as a best additive in pharmaceuticals and food industries.

\section{REFERENCES}

[1]. K. Sreekanth, D. Sravana kumar, "Study of molecular interactions in the mixtures of secondary alcohols with equimolar mixture of ethanol+formamide from acoustic and thermodynamic parameters", Journal of Chemical and Pharmaceutical Research, Vol.3, Issue.4, pp.29 - 4, 2011.

[2]. D. Bala karuna Kumar, C. Ramesh babu, "Ultrasonic investigation of molecular associations in the binary mixtures of NMP with substituted benzenes at 308.15, 318.15 K and atmospheric pressure", Journal of Chemical and Pharmaceutical Research, Vol. 3, Issue.5, pp.274 - 280,2011.

[3]. M. Jorg, A. Ghoneium, G. Turhe, M. Stockhausen, "Dielectric relaxation of some N, N-disubstituted amides", Physics and Chemistry of Liquids, Vol.29, Issue.4, pp.263-271, 1995.

[4]. S.B. Ambomase, S. Tripathy, "Studies on Water - Polymer Interactions in the Presence of Aceclofenac at 298.15 K", E-Journal of Chemistry, Vol. 8, Issue.1, pp. 63 -70, 2011. 
[5]. V. Babak, I. Lukina, G.Vikhoreva, J. Desbrieres and M. Rinaudo, "Interfacial properties of dynamic association between chitin derivatives and surfactants", Colloids and Surfaces A: physicochemical and engineering aspects, Vol. 147, Issue.1, pp.139 -148. 1999.

[6]. J. Desbrieres, M. Rinaudo, V. G. Babak and G.Vikhoreva, "Surfactant polyelectrolyte complexes on the basis of chitin", Polymer Bulletin, Vol.39, pp.209, 1997.

[7]. A. Bhattacharyya, F. Monroy, D. Langevin and J. F. Argillier, "Surface Rheology and Foam Stability of Mixed Surfactant - Polyelectrolyte Solutions", Langmuir, Vol.16, Issue.23, pp. 8727- 8732, 2000.

[8]. E. Junquera, G.Tardajos, E. Aicart, "Effect of the presence of. Beta-cyclodextrin on the micellization process of sodium dodecyl sulfate or sodium perfluorooctanoate in water", Langmuir, Vol.9, Issue.5, pp.1213-1219, 1993.

[9]. M. Alauddin, R.E. Verrall, "Ultrasonic velocity, apparent molar adiabatic compressibility and solubilization studies of aqueous solutions of cetyltrimethylammonium bromide as a function of surfactant and solubilization concentrations and temperature", The Journal of Physical Chemistry, Vol.93, Issue.9, pp.3724-3728, 1989.

[10]. J. E Lofroth, L. Johnson, “Interactions between surfactants and polymers'. I: HPMC”, In Trends in Colloid and Interface Science, Vol. 84, pp.73 $-77,1991$.

[11]. R.G. Zhbankova, D.K. Buslova, N.I. Sushkoa, "Structural physico-chemistry of polysaccharide molecular vibrational spectra and structure of water soluble cellulose and starch ethers", Journal of Molecular Structure, Vol.706, pp.133-139, 2004.

[12]. Haruko Takaya, Susumu Nii, Fumio Kawaizumi and Katsuroku Takahashi, Ultra Sonochemistry, Vol.12, Issue.6, pp. 483-487, 2005.

[13]. Andra Dedinaite, Robert Meszaros, Per M Claesson, Journal of Physical Chemistry B, Vo.108, pp.11645-1653, 2004.

[14]. R. Nagarajan, E. Kalpaki, "Micro domains in Polymer Solution”, Plenum, NewYork, pp.369, 1985.

[15]. Mayyas AI. Remaw, Journal of Applied Science, Vol.12, Issue.8, pp. 727 -735, 2012.

[16]. R. Palani. S.Balakrishnan, "Acoustical properties of ternary mixtures of 1-alkanols in di-isopropyl ether and 2,2,2-trifluoroethanol mixed solvent", Indian Journal of Pure Applied Physics, Vol.48, pp.544 - 650, 2010.

[17]. B. Saleha Begum, H. Sudhakar, "Viscosity, Ultrasonic Velocity and Refractive Index Study of Chitosan/PVA Blend in Aqueous Acetic Acid Solutions at Three Distinct Temperatures", Bulletin of Pharmaceutical Research, Vo1.1, Issue.2, 2017.

[18]. Bogdan Stefane, Andrei Perdith, European Journal of Chemistry, Vol. 30, pp. 5870 - 5883, 2010.

[19]. J.F. Comesane, J.J. Ofero, E. Garcia, "Densities and viscosities of ternary systems of water + glucose + sodium chloride at several temperatures", Journal of Chemical and Engineering Data, Vol.48, Issue.2, pp. 362-366, 2003.

[20]. S. Punitha, R. Uvarani, A. Panneerselvam and S. Nithiyanantham, "Physico-chemical studies on some saccharides in aqueous cellulose solutions at different temperatures-Acoustical and FTIR analysis", Journal of Saudi Chemical Society, Vol.18, Issue.5, pp.657-665, 2014.

[21]. P.K. Banipal, A.K.Chakal, T.S. Banipal, "Studies on volumetric properties of some Saccharides in aqueous Potassium Chloride solutions over temperature range (288.15 to 318.15) K", The Journal of Chemical Thermodynamics, Vol.41, Issue.4, pp. 452-483, 2009.

[22]. M. Umadevi, R. Kesavasamy, "Molecular interaction studies on ester with Cyclohexane in alcohol at 303, 308 and 313 K", International Journal of Chemical Environmental and Pharmaceutical Research, Vol.3, pp.72 - 82, 2012.

[23]. N. Punitha, C. Rakkappan, International conference and exhibition on Ultrasonic (ICEU - 99), New Delhi. pp. $221,1999$.

[24]. K. Seethalakshmi, J. Vasantha Rani, "A Comprehensive Analysis of Solvation Number, Internal Pressure and Equivalent Conductance of Some Imidazolium Salts”, International Journal of Science and Research, vol. 6, pp. 2190-2193, 2017.

[25]. I.B. Berlman, Hand book fluorescence spectra of aromatic molecules, Academic Press, New York, 1965.

[26]. S.G. Schulman, Fluorescence and Phosphorescence Spectroscopy. Photochemical principles and practice, Pergamon press, Oxford, 1977.

[27]. S. Priyanka, O.P.Chimankar, "Intermolecular Interaction in the Binary Mixture of B-alanine with Water at 323K", International Journal of Scientific Research in Physics and Applied Sciences, Vol.1, Issue.1, pp. 2348 - 3423, 2013.

\section{AUTHORS PROFILE}

Dr.A.PANNEERSELVAM in pursed M.Sc Physics from Bharathidasan University, Trichy, India in 2003. M.Phil and Ph.D. Physics from Annamalai University, Chidambaram, India in 2005 and 2008. He is currently working as Professor in Department of Physics from Paavai Engineering College, Pachal, and Tamilnadu, India since 2017. He has Produced $5 \mathrm{Ph} . \mathrm{D}$ Scholar in the field of material science, Ultrasonic and Spectroscopy. He has guiding $7 \mathrm{Ph} . \mathrm{D}$ Scholar in the field of material science. He has published more than 25 research papers in reputed international journals and conferences and it's also available online. His main

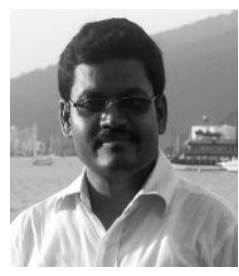
research work focuses on Ultrasonic and Spectroscopy, Thin Films, and Nanomaterials. He has 15 years of teaching experience and 10 years of research experience. He has received young scientist award 2017.

Dr.V.Karikalan in pursed M.Sc. and Ph.D. Physics from Annamalai University, Tamilnadu in 2007 and Anna university, Chennai in 2019. He is currently working as PG Assistant in Physics, Government Model School, Salem and Tamilnadu. He has published 3 research papers. His main research work to focuses on Ultrasonic and Spectroscopy. He has 10 years of teaching experience and 5 years of research experience. He has qualified SLET, SET and NET examination.

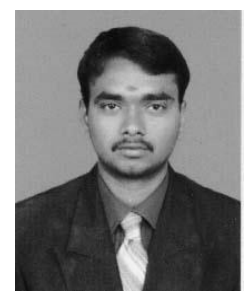

